\title{
CORRESPONDENCE
}

The Annual Census of Psychiatric Staffing (Royal College of Psychiatrists, 1995, 1996, 1997) reports reasons for consultant vacancies such as retirement, new post provision, moving to a different post and a miscellaneous 'other' group. For the years 1994 to 1996 for England, Wales and Scotland, the proportion of consultant psychiatrist taking retirement (excluding on illness grounds) and leaving a vacant post has reduced from 24.5 to $13.7 \%$ of the total vacant posts across all specialities. While some vacancies arise from provision of new posts (18.9 to $20.5 \%$ from 1994 to 1996 ), other than the other/ miscellaneous group (36.9\% in 1996) the largest proportion (22.4\% in 1994 to $23.0 \%$ in 1996$)$ are due to consultants taking different posts. This is backed up by data from College Assessors' reports on Consultant Advisory Appointment Committees for 1996 suggesting that the successful applicant was already a consultant in, for example, $47.1 \%$ of general adult psychiatry appointments.

I would speculate that vacant posts will become a hard core of 'difficult-to-fill', unappealing jobs since colleagues have either retired early from them, or others have moved from them to more attractive or lucrative positions. Therefore I would suggest that it is not just a question of tempting back prematurely retired colleagues of persuading more doctors to enter psychiatry (Storer, 1997) but encouraging trusts to be creative in their initiative to encourage current postholders to stay or prospective ones to apply.

Royal College of Psychiatrists (1995) Annual Census of Psychiatric Staffing 1994, Occasional Paper OP30. London: Royal College of Psychiatrists.

- (1996) Annual Census of Psychiatric Staffing 1995 Occasional Paper OP34. London: Royal College of Psychiatrists.

- (1997) Annual Census of Psychiatric Staffing 1996 Occasional Paper OP38. London: Royal College of Psychiatrists.

STORER, D. (1997) Things have to get better. Psychiatric Bulletin. 21, 737-738.

JoHN MilTon, Research Fellow in Psychiatry, Department of Psychiatry, Duncan Macmillan House, Nottingham NG3 6AA

\section{The Internet and psychiatry}

Sir: Senior et al (Psychiatric Bulletin, December 1997, 21, 775-778) correctly highlight the importance of the Internet as an aid to psychiatric clinicians and researchers. The World Wide Web (WWW) is a communications phenomenon that could facilitate the detection, management and understanding of mental disorders (Huang \& Alessi, 1996).

The Computers in Psychiatry Special Interest Group has a web site (http://www.ex.ac.uk/ cimh) that not only provides up-to-date descriptions of computer software useful to psychiatry but also supplies information to people with mental health problems (Littlejohns \& Briscoe, 1996). Since 1997 the site has posted the College's acclaimed "Help is at Hand" leaflet series, found at http://www.ex.ac.uk/cimh/ help.

Covering topics ranging from alcoholism to schizophrenia, they provide clear information about disorders supplemented by contact addresses and telephone numbers of relevant national support organisations. The site is visited about 2000 times per week. As computers become fully integrated into everyday life, Internet-based educational material will prove an invaluable information source for people with mental health problems.

The College has demonstrated an awareness of the opportunities afforded by the WWW. It has an obligation to ensure these opportunities are optimised to the benefit of those who need them. To this end, we are pleased to report that meetings are taking place to plan the development of a College site. We would be pleased to hear from Members with ideas about what such a site should contain.

Huang, M. P. \& Alessi, N. E. (1996) The Internet and the future of psychiatry. American Journal of Psychiatry. 153, 861-869.

LittlejohNS, C \& BRiscoe, M. (1996) The information superhighway and psychiatry. Psychiatric Bulletin, 20. 146-148.

RICHARD A. POWELl, and MARTIN BRISCOE, Department of Mental Health, PGMS, University of Exeter, Wonford House Hospital, Dryden Road, Exeter, England EX2 5AF

\section{Risk assessment}

Sir: Guidelines like the recent College report on risk assessment and management (Royal College of Psychiatrists, 1996) are frequently considered codes of professional practice in legal proceedings when something goes wrong. The report mentions that some factors are unreliable predictors of risk to harm to others. I am concerned about the validity of most of the factors included in the assessment and about the false positives likely to be detected as a result. Moreover, diagnostic categories have not been discriminated: 'psychiatric patients' is the term used throughout the report. Thus, there is an implicit inclusion of psychopathic disorder (used here as defined in the Mental Health Act 1983, and when psychopathic disorder is the main/only diagnosis).

Current classifications do not include psychopathic disorder in the set of (mental) illnesses. Also, the external evidence on the effectiveness of 